\title{
PENGARUH MOTIVASI KERJA TERHADAP ORGANIZATIONAL CITIZENSHIP BEHAVIOR DAN KINERJA PEGAWAI
}

(Studi pada Dinas Pendidikan Kota Palangka Raya)

\author{
Sri Agustin Permata Sari \\ Fakultas Ekonomi dan Bisnis \\ Universitas Palangka Raya
}

Email: sriagustinps11@gmail.com

\begin{abstract}
Abstrak:
Tujuan- Penelitian ini bertujuan untuk memberikan penjelasan secara empiris tentang pengaruh motivasi kerja terhadap organizational citizenship behavior dan kinerja pegawai. Desain/Metodelogi/Pendekatan- Metode penelitian yang digunakan deskriptif-kuantitatif. Populasi seluruh pegawai Dinas Pendidikan Kota Palangka Raya yang berjumlah 116 orang dengan sampel yang terdiri dari 90 responden dengan teknik simple random sampling. Dianalisis dengan software SmartPLS 3.2.9.

Hasil Penelitian- Menunjukkan bahwa motivasi kerja berpengaruh positif dan signifikan terhadap organizational citizenship behavior dan kinerja pegawai di Dinas Pendidikan Kota Palangka Raya.
\end{abstract}

\section{Kata Kunci: Motivasi Kerja, Organizational Citizenship Behavior, dan Kinerja Pegawai.}

\section{The Effect of Work Motivation on Organizational Citizenship Behavior and Employee Performance \\ (Study at the Education Office of Palangka Raya City)}

\begin{abstract}
:
Purpose- This study aims to provide an empirical explanation of the effect of work motivation on organizational citizenship behavior and employee performance.

Design/Methodology/Approach-The research method used is descriptive-quantitative. The population of all employees of Education Office of Palangka Raya City found 116 people with a sample consisting of 90 respondents with simple random sampling technique. Analyzed with SmartPLS 3.2.9 software.

Finding- Showes that work motivation has a positive and significant effect on organizational citizenship behavior and on employee performance in the Education Office of Palangka Raya City.
\end{abstract}

Keywords: Work Motivation, Organizational Citizenship Behavior, and Employee Performance 


\section{PENDAHULUAN}

Pandemi Covid-19 ini telah membuat adanya perubahan-perubahan diberbagai bidang seperti bidang kesehatan, perekonomian maupun pendidikan. Akibat dari perubahan tersebut menuntut agar organisasi bisa melakukan tugas dan pekerjaannya dengan mempunyai daya kemampuan adaptasi akan perubahan yang terjadi.

Sumber daya manusia merupakan faktor yang sangat sentral dalam organisasi dalam menjalankan sistem pelayanan publik. Maka dari itu penting untuk mengetahui apa saja yang menjadi faktor yang mempengaruhi pegawai dalam melakukan tugas dan tanggungjawabnya untuk menghasilkan kinerja yang baik sehingga tujuan dari organisasi dapat tercapai. Mathis dan Jackson dalam (Rita et.al.,2018) mengatakan bahwa terdapat tiga faktor yang dapat mempengaruhi kinerja individu, yaitu kemampuan individu untuk melakukan pekerjaannya, tingkat upaya yang dilakukan seperti motivasi kerja, dan dukungan yang diberikan organisasi kepada pegawainya. Untuk mendapatkan kinerja yang maksimal membutuhkan pegawai yang tidak hanya berperilaku sesuai dengan perannya, namun perlu adanya perilaku diluar dari peran atau deskripsi pekerjaan yang dimana perilaku tersebut dapat memberikan kontribusi terhadap hasil kinerja yang lebih baik.

Kinerja merupakan hasil kerja yang dicapai oleh individu maupun kelompok dalam suatu organisasi yang sesuai dengan wewenang dan tanggungjawab masing-masing dalam mencapai tujuan organisasi yang terkait secara legal, dan sesuai dengan moral maupun etika (Darmawan, 2013). Jika dilihat dari perbandingan capaian kinerja tahun 2017 dan tahun 2018 dapat dikatakan setiap tahunnya capaian kinerja Dinas Pendidikan Kota Palangka Raya masih tidak stabil karena adanya penurunan dibeberapa indikator kinerja utama. Maraknya pandemi Covid-19 sempat membuat instansi atau organisasi melakukan pekerjaan dengan menerapkan Work From Home (WFH) atau bekerja dari rumah. Pegawai Dinas Pendidikan Kota Palangka Raya merasakan bahwa WFH sangat mempengaruhi mereka dalam melaksanakan tugas dan pekerjaannya. Semangat atau dorongan kerja dari pegawai juga mengalami penurunan ditengah pandemi Covid-19 ini, hal tersebut dikarenakan adanya rasa cemas dan takut akan terpaparnya Covid-19 yang dirasakan oleh pegawai.

Pemberian motivasi sangat penting dilakukan oleh organisasi atau instansi agar tujuan yang akan dicapai dapat terlaksana dengan baik, pemberian motivasi tersebut juga diperlukan agar kinerja pegawainya akan dapat terus ditingkatkan (Wahyudi, 2017). Penelitian oleh Nurnaningsih (2017) menunjukkan bahwa adanya pengaruh positif dan signifikan motivasi kerja terhadap organizational citizenship behavior (OCB). Pada motivasi yang tinggi cenderung dapat meningkatkan adanya perilaku organizational citizenship behavior. Organizational citizenship behavior merupakan perilaku yang bersifat sukarela dan bukan merupakan tindakan yang terpaksa terhadap hal-hal yang mengedepankan kepentingan organisasi yang tidak berkaitan secara langsung dengan sistem reward formal (Sambung, 2014). Peran penting dari organizational citizenship behavior sangat diperlukan dalam mencapai kinerja yang lebih baik.

Berdasarkan latar belakang diatas, maka pertanyaan penelitian ini adalah apakah motivasi kerja berpengaruh terhadap organizational citizenship behavior pegawai Dinas Pendidikan Kota Palangka Raya dan apakah motivasi kerja berpengaruh terhadap kinerja pegawai Dinas Pendidikan Kota Palangka Raya.

Penelitian ini diharapkan dapat menambah wawasan mengenai teori manajemen sumber daya manusia dan sebagai informasi yang bermanfaat bagi pimpinan kantor Dinas Pendidikan Kota Palangka Raya dalam meningkatkan organizational citizenship behavior atau perilaku warga organisasi dan kinerja pegawai serta dapat menjadi masukan dalam mengambil keputusan untuk mencapai visi dan misi kantor Dinas Pendidikan Kota Palangka Raya. 
Berdasarkan uraian diatas, maka terbentuk kerangka konsep penelitian dan hipotesis sebagai berikut.

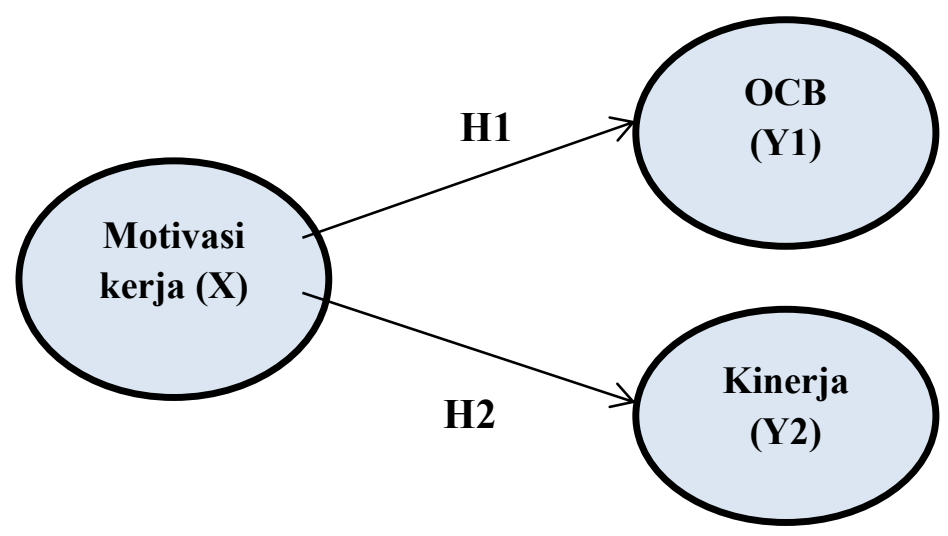

Gambar 1. Kerangka Konsep Penelitian

Berdasarkan kerangka konsep penelitian diatas, maka hipotesis atau jawaban sementara dalam penelitian ini sebagai berikut:

H1: Motivasi kerja berpengaruh terhadap organizational citizenship behavior pegawai H2: Motivasi kerja berpengaruh terhadap kinerja pegawai

\section{METODE PENELITIAN}

Penelitian ini dilaksanakan di Kantor Dinas Pendidikan Kota Palangka Raya yang baru yang beralamatkan di Jl. Ir. Soekarno atau J1. G.Obos XI (Lingkar Dalam) pada komplek Perkantoran Pemerintah Kota Palangka Raya. Penelitian ini adalah pendekatan penelitian deskriptif-kuantitaf, dengan populasi seluruh pegawai Dinas Pendidikan Kota Palangka Raya yang berjumlah 116 orang. Teknik pengambilan sampel yaitu teknik simple random sampling dan jumlah sampel 90 responden dengan menggunakan rumus Slovin dalam batas toleransi kesalahan yang ditetapkan adalah 5\% $(0,05)$. Variabel dan indikator yang digunakan dalam penelitian ini dapat dilihat pada tabel definisi operasional variabel dibawah ini:

Tabel 1. Definisi Operasional Variabel

\begin{tabular}{|c|c|c|c|}
\hline Variabel & Definisi Konsep & Indikator & Item \\
\hline $\begin{array}{c}\text { Motivasi } \\
\text { Kerja } \\
\text { (X) }\end{array}$ & $\begin{array}{l}\text { Teori Penentu Nasib Sendiri } \\
\text { merupakan teori motivasi dan } \\
\text { kepribadian yang diturunkan secara } \\
\text { empiris dalam konteks sosial yang } \\
\text { membedakan motivasi menjadi } \\
\text { otonom dan terkendali. Motivasi } \\
\text { otonom yaitu motivasi yang } \\
\text { mencerminkan minat dan nilai } \\
\text { pribadi. Motivasi terkendali yaitu } \\
\text { motivasi seseorang yang didorong } \\
\text { untuk melakukannya karena adanya } \\
\text { tekanan internal dan eksternal (Moon } \\
\text { et.al.,2019) }\end{array}$ & $\begin{array}{l}\text {-Motivasi Intrinsik (minat dan } \\
\text { kesenangan pribadi) } \\
\text {-Motivasi Teridentifikasi } \\
\text { (keyakinan dan nilai-nilai yang } \\
\text { tinggi) } \\
\text {-Motivasi Introjeksi (penghindaran } \\
\text { perasaan negatif) } \\
\text {-Motivasi Eksternal (atas } \\
\text { keterlibatan dari suatu kegiatan } \\
\text { yang datang dari pengaruh luar) }\end{array}$ & $\begin{array}{ll}\text { - } & \text { MK1 } \\
\text { - } & \text { MK2 } \\
\text { - } & \text { MK3 } \\
\text { - } & \text { MK4 } \\
\text { - } & \text { MK5 } \\
\text { - } & \text { MK6 } \\
& \\
\text { - } & \text { MK7 } \\
\text { - } & \text { MK8 }\end{array}$ \\
\hline $\begin{array}{l}\text { Organizat } \\
\text { ional Citiz } \\
\text { eship } \\
\text { Behavior } \\
\text { (Y1) }\end{array}$ & $\begin{array}{l}\text { Organizational citizenship behavior } \\
\text { yaitu perilaku yang bersifat bukan } \\
\text { paksaan dan merupakan pilihan } \\
\text { pribadi yang secara tidak langsung } \\
\text { diakui oleh struktur penghargaan } \\
\text { formal organisasi dan merupakan }\end{array}$ & $\begin{array}{l}\bullet \quad \text { OCB-I } \\
\text {-Altruisme (sikap membantu) } \\
\text {-Courtesy (membantu atau } \\
\text { mengurangi terjadi masalah) } \\
\bullet \quad \text { OCB-O }\end{array}$ & $\begin{array}{l}\text { - } \mathrm{OCB} 1 \\
\text { - } \mathrm{OCB} 2\end{array}$ \\
\hline
\end{tabular}




\begin{tabular}{|c|c|c|c|}
\hline & $\begin{array}{l}\text { perilaku yang penting dalam } \\
\text { keberhasilan fungsi organisasi. } \\
\text { Perilaku tersebut ditujukan kepada } \\
\text { individu dan organisasi (Ma } \\
\text { et.al.,2013) }\end{array}$ & $\begin{array}{l}\text {-Conscientiousness (sikap tanggung } \\
\text { jawab lebih) } \\
\text {-Sportmanship (tidak melakukan } \\
\text { hal-hal negatif) } \\
\text {-Civic Virtue ( partisipasi individu } \\
\text { terhadap organisasi) }\end{array}$ & $\begin{array}{ll}\text { - } & \text { OCB3 } \\
\text { - } & \text { OCB4 } \\
\text { - } & \text { OCB5 }\end{array}$ \\
\hline $\begin{array}{l}\text { Kinerja } \\
\text { Pegawai } \\
\text { (Y2) }\end{array}$ & $\begin{array}{l}\text { Kinerja adalah konsep } \\
\text { multikomponen dan pada tingkat } \\
\text { fundamental seseorang dapat } \\
\text { membedakan aspek proses kinerja } \\
\text { yaitu keterlibatan perilaku dari hasil } \\
\text { yang diharapkan . perilaku ini } \\
\text { menunjukkan tindakan yang } \\
\text { ditunjukkan orang untuk } \\
\text { menyelesaikan suatu pekerjaan. } \\
\text { Sedangkan aspek hasil menyatakan } \\
\text { tentang konsekuensi dari perilaku } \\
\text { individu (Pradhan } \text { et.al (2017 }\end{array}$ & $\begin{array}{l}\text {-Kinerja Tugas (tanggungjawab } \\
\text { atas tugas sesuai deskripsi } \\
\text { pekerjaan) } \\
\text {-Kinerja Adaptif (kemampuan } \\
\text { menyesuaikan diri dan memberikan } \\
\text { dukungan) } \\
\text {-Kinerja Kontekstual (sikap ekstra } \\
\text { yang tidak termasuk dalam } \\
\text { deskirpsi pekerjaannya) }\end{array}$ & $\begin{array}{ll}\text { - } & \mathrm{KP} 1 \\
\text { - } & \mathrm{KP} 2 \\
\text { - } & \mathrm{KP} 3 \\
\text { - } & \mathrm{KP} 4 \\
\text { - } & \mathrm{KP5} \\
\text { - } & \mathrm{KP} 6\end{array}$ \\
\hline
\end{tabular}

Sumber : Konsep yang dikembangkan dalam penelitian ini (2021)

Teknik pengumpulan data dalam penelitian ini menggunakan kuesioner dan wawancara. Kuesioner diukur menggunakan skala likert yang memungkinkan responden menilai item pada skala lima dengan skor 1-5 dengan urutan kategori jawaban: sangat tidak setuju, tidak setuju, netral,setuju, dan sangat setuju. Metode pengolahan data yang digunakan dalam penelitian ini adalah dengan persamaan permodelan Structural Equation Modelling (SEM) dengan pendekatan mengunakan Partial Least Square (PLS) menggunakan software SmartPLS 3.2.9.

Adapun langkah-langkah dalam analisis pendekatan PLS sebagai berikut:

\section{Evaluasi Model Pengukuran (Outer Model)}

Untuk mengetahui hubungan antara blok indikator dengan variabel latennya. Outer model digunakan untuk menguji validitas dan reliabilitas suatu model.

\section{Uji Validitas}

dilihat dari nilai average variance extracted (AVE) menunjukkan $>0,5$ atau memperlihatkan nilai outer loading dengan nilai $>0,7$ maka pengukuran dikatakan valid secara konvergen (Abdullah, 2015). Nilai loading factor 0,5-0,6 masih dianggap cukup (Ghozali \& Latan, 2015). Selanjutnya pengukuran dapat dikatakan valid secara diskriminan (Descriminant validity) dilihat dari nilai cross loadings untuk setiap variabel dan nilai fornell larcker criterion.

\section{Uji Reliabilitas}

Jika nilai composit reliability menunjukkan nilai $>0,7(\alpha>0,7)$ dan nilai output dari cronbach' alpha menunjukkan >0,6 maka kontruks tersebut dapat dikatakan reliabel (Abdullah, 2015).

\section{Evaluasi Model Struktural (Inner Model)}

Pada prinsipnya digunakan untuk menguji besarnya pengaruh antara variabel laten yang satu dengan yang lainnya. Model struktural dievaluasi dengan menggunakan $R$-square untuk kontruks dependen, Stone-Greisser Q-square test untuk predictive relevance dan uji t serta signifikansi dari koefisien parameter jalur struktural.

\section{Uji Hipotesis (Resampling bootstrapping)}

Pengujian hipotesis penelitian dilakukan dengan cara melihat nila t statistik dari inner model yang telah dibentuk sebelumnya. Menggunakan software SmartPLS 3.2.9 dengan tingkat kepercayaan yang digunakan adalah 95\% sehingga tingkat presisi atau batas ketidakakuratan sebesar $\alpha=5 \%$ atau 0,05 menghasilkan t-tabel sebesar 1,96. 


\section{HASIL DAN PEMBAHASAN}

Berdasarkan hasil kuesioner yang telah disebarkan kepada responden, maka dapat diketahui karakteristik dari responden dalam penelitian ini adalah sebagai berikut:

Tabel 2. Karakteristik Responden

\begin{tabular}{|c|c|c|}
\hline Kategori & Frekuensi & Persentase \\
\hline \multicolumn{3}{|l|}{ Jenis Kelamin } \\
\hline Laki-laki & 41 & $45,6 \%$ \\
\hline Perempuan & 49 & $54,4 \%$ \\
\hline Total & 90 & $100 \%$ \\
\hline \multicolumn{3}{|l|}{ Usia } \\
\hline$\leq 25$ Tahun & 5 & $5,56 \%$ \\
\hline 26 - 30 Tahun & 7 & $7,77 \%$ \\
\hline $31-40$ Tahun & 36 & $40 \%$ \\
\hline $41-50$ Tahun & 37 & $41,11 \%$ \\
\hline$\geq 50$ Tahun & 5 & $5,56 \%$ \\
\hline Total & 90 & $100 \%$ \\
\hline \multicolumn{3}{|l|}{ Pendidikan } \\
\hline SMA & 10 & $11,11 \%$ \\
\hline Diploma & 6 & $6,67 \%$ \\
\hline $\mathrm{S} 1$ & 72 & $80 \%$ \\
\hline $\mathrm{S} 2$ & 2 & $2,22 \%$ \\
\hline Total & 90 & $100 \%$ \\
\hline \multicolumn{3}{|l|}{ Masa Kerja } \\
\hline $2-6$ Tahun & 18 & $20 \%$ \\
\hline $7-10$ Tahun & 15 & $16,67 \%$ \\
\hline$\geq 10$ Tahun & 57 & $63,33 \%$ \\
\hline Total & 90 & $100 \%$ \\
\hline
\end{tabular}

Sumber : Data Primer diolah 2021

Berdasarkan tabel diatas, responden yang berjenis kelamin laki-laki sebanyak 41 orang atau $45,6 \%$ dan perempuan sebanyak 49 orang atau $54,4 \%$ ini menunjukkan bahwa pegawai yang berjenis kelamin perempuan lebih banyak daripada laki-laki. Untuk usia, responden yang berusia $\leq 25$ tahun berjumlah 5 orang atau 5,56\%, berusia 26-30 tahun berjumlah 7 orang atau 7,77\%, berusia 31-40 tahun berjumlah 36 orang atau $40 \%$, berusia $41-50$ tahun berjumlah 37 orang atau $41,11 \%$, dan yang berusia 50 tahun atau lebih berjumlah 5 orang atau 5,56 \% ini menunjukkan bahwa responden dalam penelitian ini lebih banyak berusia sekitar 41-50 tahun. Untuk status pendidikan, responden yang berstatus pendidikan SMA berjumlah 10 orang atau $11,11 \%$, berstatus pendidikan diploma berjumlah 6 orang atau $6,67 \%$, berstatus pendidikan S1 berjumlah 72 orang atau $80 \%$, dan yang berstatus pendidikan S2 berjumlah 2 orang atau 2,22\% ini menunjukkan bahwa responden dalam penelitian ini lebih banyak yang berstatus pendidikan S1.Terakhir dilihat dari masa kerja, responden yang telah bekerja sekitar 2-6 tahun berjumlah 18 orang atau 20\%, 7-10 tahun berjumlah 15 orang atau 16,67\%, dan yang telah bekerja sekitar 10 tahun atau lebih dari 10 tahun berjumlah 57 orang atau $63,33 \%$ ini menunjukkan bahwa banyak responden yang telah bekerja selama sekitar 10 tahun atau keatas.

\section{Hasil Uji Outer Model}

Model pengukuran yang dilakukan dengan menggunakan tabulasi data kuesioner dengan hasil sebagai berikut gambar outer model dan tabel evaluasi hasil outer model dibawah ini: 


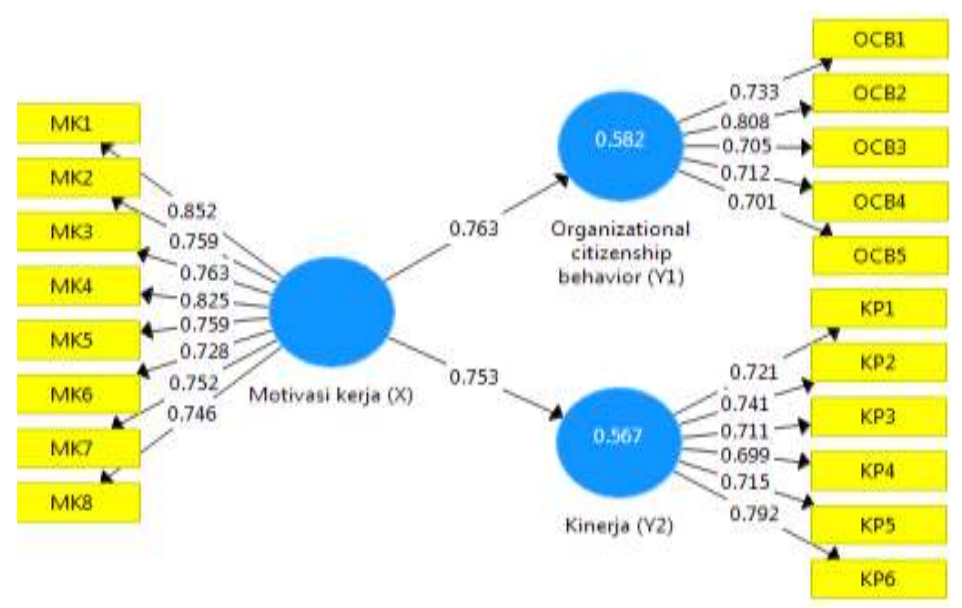

Gambar 2. Outer Model

Tabel 3. Evaluasi Hasil Outer Model

\begin{tabular}{|c|c|c|c|c|c|c|c|}
\hline Variabel & Indikator & $\begin{array}{l}\text { Outer } \\
\text { Loading }\end{array}$ & $\begin{array}{l}\text { Composite } \\
\text { Reliability }\end{array}$ & $A V E$ & $\begin{array}{l}\text { cronbach's } \\
\text { alpha }\end{array}$ & $\begin{array}{l}\text { cross } \\
\text { loading }\end{array}$ & $\begin{array}{l}\text { Fornell } \\
\text { Larcker } \\
\text { Criterion }\end{array}$ \\
\hline \multirow{8}{*}{$\begin{array}{l}\text { Motivasi } \\
\text { Kerja }\end{array}$} & Motivasi & 0,852 & \multirow{8}{*}{0,923} & \multirow{8}{*}{0,599} & \multirow{8}{*}{0,904} & \multirow{8}{*}{$\begin{array}{l}\text { Semua } \\
\text { nilai } \\
\text { indikator } \\
\text { terhadap } \\
\text { variabelny } \\
\text { a }>\text { dari } \\
\text { nilai } \\
\text { indikator } \\
\text { pada } \\
\text { variabel } \\
\text { lainnya }\end{array}$} & \\
\hline & intrinsik & 0,759 & & & & & \\
\hline & Motivasi & 0,763 & & & & & Nilai \\
\hline & Teridentifikasi & 0,825 & & & & & Akar \\
\hline & Motivasi & 0,759 & & & & & AVE $>$ \\
\hline & introjeksi & 0,728 & & & & & Nilai \\
\hline & Motivasi & 0,752 & & & & & Korelasi \\
\hline & Ekstrinsik & 0,746 & & & & & \\
\hline \multirow{3}{*}{$\begin{array}{l}\text { Organiz } \\
\text { ational } \\
\text { Citizens } \\
\text { hip Beha }\end{array}$} & Altruisme & 0,733 & \multirow{5}{*}{0,853} & \multirow{5}{*}{0,537} & \multirow{5}{*}{0,786} & \multirow{5}{*}{$\begin{array}{l}\text { Semua } \\
\text { nilai } \\
\text { indikator } \\
\text { terhadap } \\
\text { variabelny } \\
\text { a }>\text { dari } \\
\text { nilai } \\
\text { indikator } \\
\text { pada } \\
\text { variabel } \\
\text { lainnya }\end{array}$} & Nilai \\
\hline & Courtesy & 0,808 & & & & & Akar \\
\hline & $\begin{array}{l}\text { Conscientiousne } \\
\text { ss }\end{array}$ & 0,705 & & & & & AVE $>$ \\
\hline \multirow[t]{4}{*}{ vior } & Sportsmanship & 0,712 & & & & & Nilai \\
\hline & Civic Virtue & 0,701 & & & & & Korelasi \\
\hline & Kinerja & 0,721 & \multirow{6}{*}{0,873} & \multirow{6}{*}{0,534} & \multirow{6}{*}{0,829} & \multirow{6}{*}{$\begin{array}{l}\text { Semua } \\
\text { nilai } \\
\text { indikator } \\
\text { terhadap } \\
\text { variabelny } \\
\text { a }>\text { dari } \\
\text { nilai } \\
\text { indikator } \\
\text { pada } \\
\text { variabel } \\
\text { lainnya }\end{array}$} & \\
\hline & tugas & 0,741 & & & & & Nilai \\
\hline Kinerja & Kinerja & 0,711 & & & & & Akar \\
\hline \multirow[t]{3}{*}{ Pegawai } & adaptif & 0,699 & & & & & AVE $>$ \\
\hline & Kinerja & 0,715 & & & & & Nilai \\
\hline & kontekstual & 0,792 & & & & & Korelasi \\
\hline
\end{tabular}

Sumber : Outer model dalam penelitian ini 


\section{Validitas Konvergen (Convergent Validity)}

Berdasarkan tabel diatas, diketahui bahwa masing-masing indikator variabel penelitian memiliki nilai outer loading $>0,60$ dan nilai AVE (Average Variance Extracted) masingmasing variabel memiliki nilai $>0,50$. Dengan demikian dapat dikatakan pengukuran tersebut valid secara konvergen.

\section{Validitas Diskriminan (Descriminant Validity)}

Berdasarkan tabel 4 dan tabel 5 dibawah ini memiliki nilai cross loading terbesar pada variabel yang dibentuknya dibandingkan dengan nilai pada variabel laten lainnya sehingga dapat dikatakan pengukuran dalam penelitian ini memiliki validitas diskriminan yang tinggi. Dan untuk nilai akar ave dilihat dari data dibawah ini, nilainya $>0,70$ sehingga pengukuran dapat dikatakan valid secara diskriminan dengan baik.

Tabel 4. Cross Loadings

\begin{tabular}{|c|c|c|c|}
\hline Item & $\begin{array}{c}\text { Kinerja } \\
\text { (Y2) }\end{array}$ & Motivasi kerja (X) & $\begin{array}{c}\text { Organizational citizenship behavior } \\
\text { (Y1) }\end{array}$ \\
\hline KP1 & 0,721 & 0,637 & 0,631 \\
\hline KP2 & 0,741 & 0,569 & 0,607 \\
\hline KP3 & 0,711 & 0,415 & 0,471 \\
\hline KP4 & 0,699 & 0,369 & 0,494 \\
\hline KP5 & 0,715 & 0,494 & 0,425 \\
\hline KP6 & 0,792 & 0,689 & 0,789 \\
\hline MK1 & 0,577 & 0,852 & 0,605 \\
\hline MK2 & 0,461 & 0,759 & 0,485 \\
\hline MK3 & 0,579 & 0,763 & 0,561 \\
\hline MK4 & 0,636 & 0,825 & 0,572 \\
\hline MK5 & 0,581 & 0,759 & 0,562 \\
\hline MK6 & 0,542 & 0,728 & 0,660 \\
\hline MK7 & 0,610 & 0,752 & 0,593 \\
\hline MK8 & 0,642 & 0,746 & 0,652 \\
\hline OCB1 & 0,545 & 0,592 & 0,733 \\
\hline OCB2 & 0,753 & 0,691 & 0,808 \\
\hline OCB3 & 0,589 & 0,477 & 0,705 \\
\hline OCB4 & 0,494 & 0,507 & 0,712 \\
\hline OCB5 & 0,536 & 0,486 & 0,701 \\
\hline
\end{tabular}

Sumber : Cross Loadings untuk penelitian ini

Tabel 5. Fornell-Larcker Criterion

\begin{tabular}{lccc|}
\hline & $\begin{array}{c}\text { Kinerja } \\
\text { (Y2) }\end{array}$ & $\begin{array}{c}\text { Motivasi } \\
\text { kerja (X) }\end{array}$ & $\begin{array}{c}\text { Organizational citizenship } \\
\text { behavior (Y1) }\end{array}$ \\
\hline Kinerja (Y2) & 0,731 & & \\
\hline Motivasi kerja (X) & 0,753 & 0,774 & \\
\hline $\begin{array}{l}\text { Organizational citizenship } \\
\text { behavior (Y1) }\end{array}$ & 0,805 & 0,763 & 0,733 \\
\hline
\end{tabular}

Sumber : Fornell-Larcker Criterion untuk penelitian ini

\section{Reliabilitas}

Berdasarkan data pada tabel 3, dapat diketahui nilai composite reliability dari masingmasing variabel nilainya $>0,70$, dan diketahui cronbach's alpha dari masing-masing 
variabel nilainya $>0,70$. Hasil ini menunjukkan bahwa pengukuran dalam penelitian ini memiliki tingkat reliabilitas yang baik dan dapat digunakan.

\section{Hasil Uji Inner Model}

Dari Inner model diketahui evaluasi path coefficient (koefisien jalur) yang digunakan untuk mengetahui seberapa kuat efek atau pengaruh variabel eksogen terhadap variabel endogen. Berikut ini evaluasi hasil inner model dapat dilihat pada tabel 6 dibawah ini.

Tabel 6. Evaluasi Hasil Inner Model

\begin{tabular}{|c|c|c|c|c|}
\hline Variabel Laten & Indikator & VIF & $\begin{array}{c}\text { Koefisien } \\
\text { Determinasi } \\
\left(R^{2}\right)\end{array}$ & $\begin{array}{c}\text { Cross-validates redundancy } \\
\left(Q^{2}\right)\end{array}$ \\
\hline \multirow{8}{*}{ Motivasi Kerja } & \multirow{2}{*}{$\begin{array}{l}\text { Motivasi } \\
\text { intrinsik }\end{array}$} & 4,287 & & \\
\hline & & 3,978 & & \\
\hline & \multirow{2}{*}{$\begin{array}{c}\text { Motivasi } \\
\text { Teridentifikasi }\end{array}$} & 2,206 & & \\
\hline & & 3,227 & & \\
\hline & \multirow{2}{*}{$\begin{array}{l}\text { Motivasi } \\
\text { introjeksi }\end{array}$} & 2,153 & & \\
\hline & & 2,013 & & \\
\hline & \multirow{2}{*}{$\begin{array}{l}\text { Motivasi } \\
\text { Ekstrinsik }\end{array}$} & 2,365 & & \\
\hline & & 2,691 & & \\
\hline \multirow{5}{*}{$\begin{array}{c}\text { Organizational } \\
\text { Citizenship } \\
\text { Behavior }\end{array}$} & Altruisme & 1,707 & \multirow{5}{*}{0,582} & \multirow{5}{*}{0,280} \\
\hline & Courtesy & 1,974 & & \\
\hline & Conscientiousness & 1,647 & & \\
\hline & Sportsmanship & 1,730 & & \\
\hline & Civic Virtue & 1,524 & & \\
\hline \multirow{6}{*}{$\begin{array}{l}\text { Kinerja } \\
\text { Pegawai }\end{array}$} & \multirow{2}{*}{$\begin{array}{c}\text { Kinerja } \\
\text { tugas }\end{array}$} & 1,607 & \multirow{6}{*}{0,567} & \multirow{6}{*}{0,266} \\
\hline & & 1,775 & & \\
\hline & \multirow{2}{*}{$\begin{array}{l}\text { Kinerja } \\
\text { adaptif }\end{array}$} & 1,862 & & \\
\hline & & 2,016 & & \\
\hline & \multirow{2}{*}{$\begin{array}{c}\text { Kinerja } \\
\text { kontekstual }\end{array}$} & 1,918 & & \\
\hline & & 1,862 & & \\
\hline
\end{tabular}

Sumber : Inner model dalam penelitian ini

Berdasarkan data pada tabel diatas, dilihat dari nilai VIF telah memenuhi syarat yaitu dibawah angka 5 yang dapat diartikan tidak terjadi multicolliniearity pada masing-masing indikator variabel. Diketahui nilai R-square untuk organizational citizenship behavior (Y1) sebesar 0,582 yang berarti variabel motivasi kerja (X) mempengaruhi variabel organizational citizenship behavior (Y1) sebesar 0,582 atau 58,2 \%, sedangkan 41,8 \% dipengaruhi oleh variabel lain diluar penelitian ini. Sedangkan untuk variabel kinerja pegawai (Y2) nilai R-square sebesar 0,567 yang berarti motivasi kerja (X) mempengaruhi variabel kinerja pegawai (Y2) sebesar 0,567 atau 56,7\% sedangkan 43,3\% dipengaruhi oleh variabel lainnya diluar dari penelitian ini. Perhitungan Q-square pada tabel diatas menghasilkan nilai dari kontruks variabel kinerja sebesar 0,266 atau lebih besar dari 0 dan organizational citizenship behavior dengan nilai 0,280 atau lebih besar dari 0. Berdasarkan hasil tersebut dapat dikatakan bahwa kedua kontruks akurat.

Uji Hipotesis

Untuk mengukur signifikansi terdukung atau diterimanya hipotesis dapat digunakan perbandingan nilai T-tabel dan T-statistik serta nilai $P$ Values. Berikut ini adalah hasil uji hipotesis dalam penelitian ini yang dapat dilihat pada tabel 7 berikut ini:

Tabel 7 Path Coefficient

\begin{tabular}{cccccc}
$\begin{array}{c}\text { Original } \\
\text { Sample }\end{array}$ & $\begin{array}{c}\text { Sample } \\
\text { Mean }\end{array}$ & $\begin{array}{c}\text { Standard } \\
\text { Deviation }\end{array}$ & $\begin{array}{c}T \\
\text { Statistics }\end{array}$ & $\begin{array}{c}P \\
\text { Values }\end{array}$ & Hasil \\
\hline
\end{tabular}




\begin{tabular}{lcccccc}
\hline $\begin{array}{l}\text { Motivasi Kerja (X) - } \\
\begin{array}{l}\text { Organizational Citizenship } \\
\text { Behavior (Y1) }\end{array}\end{array}$ & 0,763 & 0,774 & 0,053 & 14,421 & 0,000 & Diterima \\
\hline $\begin{array}{l}\text { Motivasi Kerja ->Kinerja } \\
\text { Pegawai(Y2) }\end{array}$ & 0,753 & 0,764 & 0,044 & 16,997 & 0,000 & Diterima \\
\hline
\end{tabular}

Sumber : Path coefficient dalam penelitian ini

Untuk mengetahui apakah hipotesis dapat diterima dan terdapat pengaruh positif dan signifikan adalah dengan melihat nilai t-statistik $>$ t-tabel $(1,96)$, nilai original sample positif atau negatif dan nilai $p$ values $<0,05$.

\section{Pengujian Hipotesis 1}

Untuk melihat apakah motivasi kerja (X) berpengaruh terhadap organizational citizenship behavior (Y1). Berdasarkan tabel diatas, nilai original sample adalah positif yaitu sebesar 0,763 , dilihat dari nilai t-statistik sebesar 14,421 yang artinya t-statistik $>\mathrm{t}$ tabel $(14,421>1,96)$ dengan nilai $p$ values $0,000(0,000<0,05)$. Dapat disimpulkan bahwa motivasi kerja (X) memiliki pengaruh positif dan signifikan terhadap organizational citizenship behavior (Y1).

\section{Pengujian Hipotesis 2}

Untuk melihat apakah motivasi kerja (X) berpengaruh terhadap kinerja (Y2). Berdasarkan tabel diatas, nilai original sample adalah positif yaitu sebesar 0,753 , dilihat dari nilai t-statistik 16,997 sebesar yang artinya t-statistik $>\mathrm{t}$-tabel $(16,997>1,96)$ dengan nilai $p$ values $0,000(0,000<0,05)$. Dapat disimpulkan bahwa motivasi kerja (X) memiliki pengaruh positif dan signifikan terhadap kinerja (Y2).

\section{Pembahasan}

\section{Pengaruh Motivasi kerja terhadap organizational citizenship behavior}

Bahwa motivasi kerja yang tinggi akan mempengaruhi timbulnya perilaku organizational citizenship behavior dan dapat dikatakan motivasi kerja yang tinggi dapat meningkatkan perilaku organizational citizenship behavior. Berdasarkan penilaian pegawai, motivasi kerja yang digambarkan dengan adanya rasa nyaman akan pekerjaannya sehingga pegawai yang memiliki sifat positif terhadap organisasi akan semakin menampilkan perilaku organizational citizenship behavior yaitu perilaku saling membantu menyampaikan informasi dan berita kepada rekan kerja lainnya. Dalam penelitian ini, indikator untuk mengukur organizational citizenship behavior lebih besar terlihat pada OCB-I yaitu perilaku yang ditujukan atau berorientasi pada individu.

Hal ini sejalan dengan penelitian oleh Danendra, A. N. B., \& Mujiati, N.W.(2016) Motivasi berpengaruh positif dan signifikan pada organizational citizenship behavior. Penelitian oleh Ibrahim, M.A., \& Aslinda, A. (2015) menunjukkan bahwa motivasi intrinsik dan motivasi ekstrinsik berpengaruh positif terhadap organizational citizenship behavior.

\section{Pengaruh Motivasi kerja terhadap kinerja}

Bahwa semakin tinggi motivasi kerja yang dimiliki oleh pegawai maka semakin meningkat juga kinerja pegawainya. Berdasarkan penilaian pegawai, kinerja yang digambarkan saling menjaga hubungan baik dengan rekan kerja lainnya yang mempengaruhi mereka dalam melakukan tugas, dapat tercapai karena tingginya motivasi dari dalam diri pegawai yaitu rasa nyaman akan pekerjaannya dan pekerjaan memungkinkannya untuk mencapai tujuan hidupnya sehingga dapat melaksanakan pekerjaan dengan baik dan tujuan dari organisasi dapat tercapai.

Hal ini sejalan dengan penelitian oleh Wahyudi (2017) menunjukkan motivasi berpengaruh signifikan terhadap kinerja. Penelitian oleh Muslih (2012) mengungkapkan bahwa pegawai yang memilki motivasi yang tinggi maka akan melakukan pekerjaannya dengan semangat dan bergairah sehingga kinerja akan menjadi optimal dan dapat mendukung tercapainya tujuan organisasi dengan efektif dan efisien. 


\section{Keterbatasan Penelitian}

Ukuran sampel yang kecil dari satu instansi pemerintahan, yang kemungkinan belum dapat digeneralisasikan ke instansi pemerintah lainnya dan terdapatnya item pernyataan yang belum sesuai untuk digunakan sebagai indikator untuk mengukur suatu variabel. Item pernyataan tersebut adalah OCB4, OCB5, KP5 dan KP6.

\section{KESIMPULAN}

Berdasarkan hasil analisis data dan pengolahan data yang telah dilakukan, penulis dapat menyimpulkan bahwa motivasi kerja berpengaruh positif dan signifikan terhadap kinerja pegawai Dinas Pendidikan Kota Palangka Raya, motivasi kerja berpengaruh positif dan signifikan terhadap organizational citizenship behavior pegawai Dinas Pendidikan Kota Palangka Raya, organizational citizenship behavior berpengaruh positif dan signifikan terhadap kinerja pegawai Dinas Pendidikan Kota Palangka Raya, dan organizational citizenship behavior mampu memediasi hubungan antara motivasi kerja dengan kinerja pegawai Dinas Pendidikan Kota Palangka Raya.

Dan saran yang penulis dapat berikan untuk Dinas Pendidikan Kota Palangka Raya berdasarkan hasil penelitian, yaitu: motivasi kerja pegawai masih harus ditingkatkan, perlu diberikan semangat dan dorongan kepada pegawai bahwa dalam melakukan tugas, terjadinya kesalahan merupakan suatu yang wajar namun jika dalam batas kesalahan tertentu dan adanya keinginan untuk memperbaikinya. Penting adanya pemberian pelatihan dan pengembangan kepada pegawai, pentingnya terjalin komunikasi yang baik dan memperhatikan kesejahteraan pegawai.

Perilaku warga organisasi atau OCB juga harus ditingkatkan, perlu adanya komunikasi yang baik sehingga dari komunikasi tersebut pimpinan dapat mengetahui apa yang menjadi keluhan dari pegawainya. Pegawai harus benar-benar mengetahui bahwa mereka telah diberikan tanggungjawab dalam menggunakan dengan maksimal, merawat dan menjaga fasilitas yang telah diberikan untuk menunjang pelaksanaan kerja.

Kinerja pegawai juga penting untuk terus ditingkatkan, terjalinnya komunikasi dan hubungan yang baik antara pimpinan dengan pegawai maupun antara sesama rekan kerja sangat penting. Terlebih ditengah pandemi covid-19 ini, saling mendukung dan membangun kerjasama yang baik sangat dibutuhkan sehingga apapun masalah yang dihadapi oleh organisasi dapat ditangani bersama. Pemberian apresiasi kepada pegawai juga penting dilakukan, apresiasi atas kontribusi yang telah mereka berikan untuk kemajuan suatu organisasi.

Kemudian bagi peneliti selanjutnya dapat memperluas subjek penelitiannya agar hasil penelitian tersebut dapat digenerelisasikan. Dapat menggunakan indikator yang sesuai dengan keadaan subjek dan membedakan OCB untuk perusahaan swasta dan pelayanan publik.

\section{DAFTAR PUSTAKA}

\section{Abdullah. (2015). Metodologi Penelitian Kuantitatif. Yogyakarta: Aswaja Pressindo}

Danendra, A. N. B., \& Mujiati, N. W. (2016). Pengaruh Motivasi, Kompensasi Dan Komitmen Organisasional Terhadap Organizational Citizenship Behavior (OCB). EJurnal Manajemen, 5(10).

Darmawan, R. B. (2013). Pengaruh Lingkungan Kerja, Stres Kerja Dan Motivasi Terhadap Kinerja Karyawan (Studi Kasus pada PT.BPRS Sukowati Sragen). Journal of Chemical Information and Modeling, 53(9), 1689-1699. 
Ghozali. dan Latan. (2015). Partial Least Squares: Konsep, Teknik dan Aplikasi Menggunakan Program SmartPLS 3.0. Semarang: Badan Penerbit UNDIP.

Ibrahim, M. A., \& Aslinda, A. (2015). The effect of motivation on organizational citizenship behavior (OCB) at Telkom Indonesia in Makassar. BISNIS \& BIROKRASI: Jurnal Ilmu Administrasi dan Organisasi, 21(2), 114-120.

Ma, E., Qu, H., Wilson, M., \& Eastman, K. (2013). Modeling OCB for hotels: Don't forget the customers. Cornell Hospitality Quarterly, 54(3), 308-317.

Moon, T. W., Hur, W. M., \& Hyun, S. S. (2019). How service employees' work motivations lead to job performance: The role of service employees' job creativity and customer orientation. Current Psychology, 38(2), 517-532.

Muslih, B. (2012). Analisis Pengaruh Motivasi Terhadap Kepuasan Kerja Dan Kinerja Pegawai Di PT. Sang Hyang Seri (Persero) Regional III Malang. (Analysis of Influence Motivation Against Job Satisfaction And Employee Performance In PT. Sang Hyang Seri (Persero) Regional III . Jurnal Aplikasi Manajemen, 10(4), 799-810.

Nurnaningsih, S., \& Wahyono, W. (2017). Pengaruh Kepuasan Kerja, Motivasi Kerja Dan Komitmen Organisasi Terhadap Kinerja Melalui Organizational Citizenship Behavior (OCB) Sebagai Variabel Intervening. Economic Education Analysis Journal, 6(2), 365-378.

Pradhan, R. K., \& Jena, L. K. (2017). Employee performance at workplace: Conceptual model and empirical validation. Business Perspectives and Research, 5(1), 69-85.

Rita, M., Payangan, O. R., Rante, Y., Tuhumena, R., \& Erari, A. (2018). Moderating effect of organizational citizenship behavior on the effect of organizational commitment, transformational leadership and work motivation on employee performance. International Journal of Law and Management.

Sambung, R. (2014). Pengaruh Kepribadian Terhadap Organizational Citizenship Behavior (Ocb) Dengan Komitmen Organisasional Sebagai Intervening (Studi Pada Universitas Palangka Raya). Jurnal Manajemen dan Akuntansi, 3(1).

Wahyudi, T. P. (2017). Pengaruh Motivasi Terhadap Kinerja Karyawan Pelaksana Di Kantor Direksi PT. Perkebunan Nusantara XIII (Persero) Pontianak. Jurnal Manajemen Motivasi, 12(2), 694-700. 